\title{
Involuntary outpatient treatment: the data and controversy
} Marvin Swartz

\author{
Address: Department of Psychiatry and Behavioral Sciences, Duke University Medical Center, Box 3173, Durham, NC 27710, USA \\ from WPA Thematic Conference. Coercive Treatment in Psychiatry: A Comprehensive Review \\ Dresden, Germany. 6-8 June 2007 \\ Published: 19 December 2007 \\ BMC Psychiatry 2007, 7(Suppl I):S28 doi:10.1 186/I47I-244X-7-SI-S28
}

This abstract is available from: http://www.biomedcentral.com//47I-244X/7/SI/S28

(C) 2007 Swartz; licensee BioMed Central Ltd.

Involuntary Outpatient Commitment, also referred to as Assisted Outpatient Treatment or Community Treatment Orders, are controversial civil court procedures whereby judges may order non-adherent mentally ill individuals to comply with treatment. This presentation will summarize the data and controversy about these procedures and put them in the context of the larger debate about the use of coercion in mental health treatment. 